\title{
Exhaled Nitric Oxide Measurements in Childhood Asthma: Comparison of Two Sampling Techniques
}

\author{
IRENE HADJIKOUMI, AKBAR HASSAN, AND ANTHONY D. MILNER \\ Paediatric Department, Guy's and St Thomas' Hospital, Guy's, King's, St Thomas' School of Medicine, \\ Kings College, London, U.K.
}

\begin{abstract}
Nitric oxide (NO) is being increasingly used to assess airway inflammation in childhood. The method recommended by the American Thoracic Society workshop is for a prolonged expiration against a resistance. However, this is very difficult to apply in young children. As a result there have been a number of studies in which mixed expired gas has been collected and analyzed for NO content as this requires very little cooperation. This method has, however, yet to be fully validated. The aims of this study were to compare the two sampling techniques of exhaled NO concentrations in asthmatic and healthy children and to assess the correlation between NO levels and spirometry values in asthmatic children We studied 25 control children, mean age $11.5 \mathrm{y}$, and 20 asthmatics, mean age $12 \mathrm{y}$. The exhaled NO was sampled using both the single breath technique (SB) and by measuring the NO content in mixed expired air after 1 min tidal breathing (ME). Forced expiratory volume in $1 \mathrm{~s}\left(\mathrm{FEV}_{1}\right)$ and expiratory flow rates at $25 \%, 50 \%$, and $75 \%$ of vital capacity $\left(\mathrm{FEF}_{25}, \mathrm{FEF}_{50}, \mathrm{FEF}_{75}\right.$, respectively) were measured by compact II spirometer (best of three) in the 20 asthmatic children. The NO level was significantly higher in the asthmatics versus the control
\end{abstract}

\section{ABSTRACT}

children when measured by SB $(p=0.0015)$ but not when measured by ME ( $p=0.1913)$. The NO results measured by SB were significantly higher than ME results in the asthmatic children $(p=0.008)$. The NO levels were negatively correlated to $\mathrm{FEV}_{1}, \mathrm{FEF}_{25}, \mathrm{FEF}_{50}$, and $\mathrm{FEV}_{75}$ when measured by SB $(p<$ 0.02 ) but not when measured by ME. The SB but not the ME method for measuring expired NO discriminates between asthmatic and control children and correlates well with the degree of airway obstruction. The use of the ME technique remains unproven. (Pediatr Res 52: 745-749, 2002)
NO, nitric oxide
ENO, exhaled nitric oxide
SB, single breath technique
ME, measuring the NO content in mixed expired air after 1 min tidal breathing
$\mathbf{F E V}_{1}$, forced expiratory volume in $1 \mathrm{~s}$
$\mathbf{F E F}_{\mathbf{2 5 / 5 0 / 7 5}}$, forced expired flow rate at $25 \% / 50 \% / 75 \%$ of vital capacity, respectively

\section{Abbreviations}

The presence of NO in exhaled breath was first described by Gustaffson et al. in 1991 (1). Shortly thereafter, ENO was found in exhaled gas of patients with asthma at significantly higher levels than in nonasthmatic control subjects $(2,3)$. Levels in healthy children and those with asthma have varied widely from laboratory to laboratory (4). These variations can be explained to a large extent by the fact that peak NO levels are dependent on measurement conditions (5). Endogenous NO can be measured directly at peak flow (6) by a single breath profile of a prolonged exhalation (7) or by direct sampling of mixed expired gas collected in a reservoir such as a Douglas bag (8). The method recommended by the American Thoracic Society is to measure the NO plateau during a prolonged expiration against a defined resistance (9). This technique is

Received November 1, 2001; accepted May 22, 2002.

Correspondence: A.D. Milner, M.D., Children Nationwide Regional Neonatal Intensive Care Centre, 4th Floor, Ruskin Wing, King's College Hospital, London, SE5 9RS, U.K.; e-mail: anthony.milner@kcl.ac.uk

DOI: 10.1203/01.PDR.0000031922.23952.09 now considered to be the "gold standard" as contamination from the upper airways is avoided and consistent results are obtained provided the expiratory flow is less than $100 \mathrm{~mL} / \mathrm{s}$ (1). This requires a considerable degree of cooperation and skill; thus, alternative techniques are often used in children. Some of these have been at least partially validated against the SB technique. Jöbsis and colleagues (10) compared results from the SB technique with those from tidal breathing and simultaneous collection of expired gases in a balloon or bag $(10,11)$ for off-line analysis. However, to our knowledge there are no published data comparing the SB technique to off-line analysis of mixed expired gases collected during tidal breathing over a timed period. Thus the technique most suitable for clinical and epidemiologic studies, particularly in children too young for sophisticated cooperation, has not yet been validated.

The aims of this study were therefore 1) to compare two sampling techniques for measuring ENO concentration of expired air in asthmatic and healthy children; and 2) to assess the correlation between the measured NO levels and the spirome- 
try values in asthmatic children. The two techniques studied were the SB and ME techniques.

\section{METHODS}

Twenty-five normal control children (12 boys and 13 girls) aged 9 to $16 \mathrm{y}$ (mean, $12 \mathrm{y}$ ) and 20 asthmatic children (13 boys and 7 girls) aged 9 to $15 \mathrm{y}$ (mean, $11.5 \mathrm{y}$ ) were included in the study. All 20 children suffered from severe asthma and were being treated with high-dose inhaled steroids (mean of $1660 \mu \mathrm{g}$ daily). None of the children participating in the study received oral steroids in the 2-wk period preceding the study. They were recruited from the Children's Respiratory Clinics at Guy's and St. Thomas' Hospitals. The normal controls were children without asthma, hay fever, or eczema and were recruited from the medical pediatric ward.

The levels of NO in exhaled breath sampled by both techniques were analyzed by the principle of chemiluminescence. This method consists of reacting NO with ozone in a cooled reaction chamber that converts $\mathrm{NO}$ to $\mathrm{NO}_{2}$. This is a photochemical reaction, with the emission of light in the infrared range that can be detected by a photomultiplier tube $(12,13)$. For this study, a Sievers 280 analyzer (Sievers Instruments, Boulder, CO, U.S.A.) was used with a sampling rate of 100 $\mathrm{mL} / \mathrm{min}$. This had a $200-\mathrm{ms}$ response for $90 \%$ of full-scale deflection. The analyzer measured down to $1 \mathrm{ppb}$ with an accuracy certified by the manufacturer to be $\pm 1 \mathrm{ppb}$ over the $0-100 \mathrm{ppb}$ range. The equipment was zeroed before every study session. This was achieved by sampling air from an air cylinder that had first passed through a zero air filter scrubber (Sievers Instruments), which contained potassium permanganate and charcoal and reduced the NO to less than $1 \mathrm{ppb}$. At two approximately weekly intervals the analyzer was also calibrated against a specially prepared $\mathrm{NO}$ calibration gas consisting of $3.5 \mathrm{ppm} \mathrm{NO}$ in nitrogen (certified by BOC Special Gases, Surrey Research Park, Guildford, UK). Environmental NO was measured at each measurement session. For each child, all measurements were completed during a single half-day session.

\section{Sampling Techniques}

The SB was always used first, followed by the ME. The asthmatic children underwent spirometric measurements after completing the NO measurements. The children received no drinks or food for $1 \mathrm{~h}$ before or during the test

SB technique. The children inhaled room air to total lung capacity and then exhaled to residual volume against a fixed resistance, through a mouthpiece, while maintaining an expiratory pressure as close as possible to $20 \mathrm{~cm} \mathrm{H}_{2} \mathrm{O}$, with the help of a display on a computer screen. This produced an expiratory flow rate close to $0.1 \mathrm{~L} / \mathrm{s}$. In the profile of $\mathrm{NO}$ versus time an early NO peak was seen, followed by a plateau concentration that is claimed to most closely represent the steady uptake of NO into a constant flow of exhaled gas (14). The duration of exhalation was at least $20 \mathrm{~s}$ with an NO plateau lasting at least $10 \mathrm{~s}$. Exhalations were repeated three times, with $2 \mathrm{~min}$ of normal breathing in between, and the mean of three NO plateau levels was calculated.
Mean expired NO concentration. The children were sitting, wore nose clips, and were encouraged to breathe in a quiet and relaxed manner through a mouthpiece for a 2 -min period. The mouthpiece was attached directly to a pneumotachograph (Fleisch No. 2, Fleisch, Lausanne, Switzerland). The pneumotachograph was connected to a three-way valve. A bias airflow of $0.33 \mathrm{~L} / \mathrm{s}$ was delivered to one limb of the valve from a pressurized air cylinder. The air was passed through an activated charcoal filter to remove any NO so the inhaled air was NO free. The activated charcoal filter was checked regularly to make sure that it was still removing all the NO from the cylinder air. On no occasion did the NO level of the bias flow exceed $1 \mathrm{ppb}$, indicating that the filter functioned well throughout the study period. The remaining limb of the valve led to a further three-way tap, one limb leading to a 1001 Douglas bag and the remaining limb to atmosphere.

The pressure drop across the pneumotachograph was measured by a Validyne differential pressure transducer (Validyne Engineering, Northrich, CA, U.S.A.), the output of which was connected to a computer. In-house developed software was used to integrate the flow signal so that the tidal volumes, respiratory rate, and expired minute volume could be displayed over 1-min collection periods.

The pneumotachograph was calibrated against airflows of 0 and $20 \mathrm{~L} / \mathrm{min}$ before each study using a rotameter. The children rebreathed the NO-free bias flow for a 1-min period while the mixed expired gases were vented to atmosphere via the threeway tap. At the end of this period, the tap was turned and the mixed expired gases collected in the Douglas bag for $60 \mathrm{~s}$. At the end of this period, the tap was rotated back so that the gas within the bag was sealed. This procedure for collection was repeated three times so that three sample bags were collected for each subject. The contents of the bags were analyzed within 10 min of collection. The mean mixed expired NO concentration for three attempts was then calculated.

Spirometer. Spirometric measurements were obtained using an electronic spirometer (Vitalograph Compact II, Vitalograph, Buckingham, U.K.). This was calibrated against a 1-L syringe provided by the manufacturer. The patients performed this test while standing, using a cardboard mouthpiece $2.7 \mathrm{~cm}$ in diameter). Each patient performed three acceptable blows after a period of training. The forced vital capacity, $\mathrm{FEV}_{1}, \mathrm{FEF}_{25}$, $\mathrm{FEF}_{50}$, and $\mathrm{FEF}_{75}$ were recorded. The best of three successful attempts was recorded. The results were corrected to body temperature, saturated pressure, and expressed as a percentage predicted for height and sex using the data of Polgar and Promadhat (15).

\section{Ethics}

The project was considered and passed by the St. Thomas' Hospital Ethics Committee. Verbal consent was obtained from the children and written consent from at least one of the parents. On all occasions at least one of the children's parents were present. 


\section{Analyses}

The Wilcoxon signed rank test was used to compare the results of the NO measurements obtained by the two techniques in both the control and asthmatic children. Linear regression analysis was used to determine the relationship between the NO measurements and the spirometry results. A $p$ value of less than 0.05 was accepted as significant. Results are presented as mean $\pm \mathrm{SD}$.

\section{RESULTS}

The mean ENO concentration in the asthmatic group was $54.52 \pm 44.1 \mathrm{ppb}$ when measured by the SB and $23.97 \pm 12.0$ ppb by the ME ( $p=0.008$; Fig. 1$)$. In only three of the asthmatic children was the ENO higher when measured by the ME than by the SB technique. In the control children, the mean ENO was $20.23 \pm 14.6 \mathrm{ppb}$ by the SB and $17.98 \pm 9.8 \mathrm{ppb}$ by the ME (Fig. 2). This difference was not significant, with 10 of the 25 control children having higher ME results $(p=0.19)$. The NO level was significantly higher in the asthmatic children versus the control children when measured by the SB ( $p=$ $0.0015)$ but not when measured by the $\operatorname{ME}(p=0.19)$.

The linear regression analysis showed no statistically significant association between the NO results obtained by the two sampling methods either in the asthmatic $(p=0.47)$ or the control $(p=0.73)$ children.

The spirometry results of the $\mathrm{FEV}_{1}, \mathrm{FEF}_{25}, \mathrm{FEF}_{50}$, and $\mathrm{FEV}_{75}$ showed a highly significant negative correlation with the NO levels when measured by SB $(p<0.05)$ (Fig. 3). None of the correlations reached significance when the ENO was measured by the ME technique (Fig. 4).

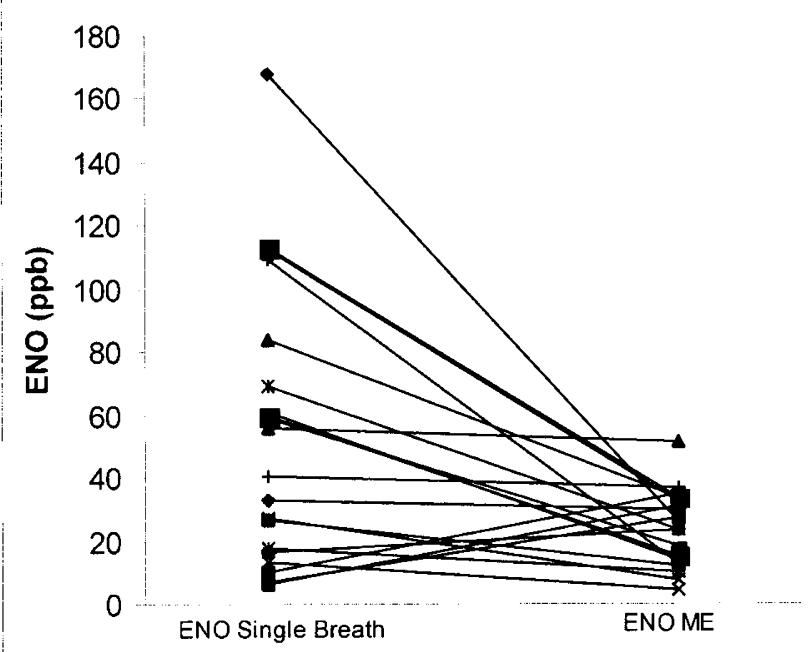

Figure 1. Comparison of ENO in 20 asthmatic children sampled by the SB and ME techniques. Measurements of ENO using the SB and ME techniques in the asthmatic group are shown. The mean ENO when measured by the SB was $55.52 \pm 44.1 \mathrm{ppb}$ and $23.97 \pm 12.0 \mathrm{ppb}$ by the $\mathrm{ME}(p=0.008)$. In only three of the children was the ENO higher when measured by the ME than by the SB technique.

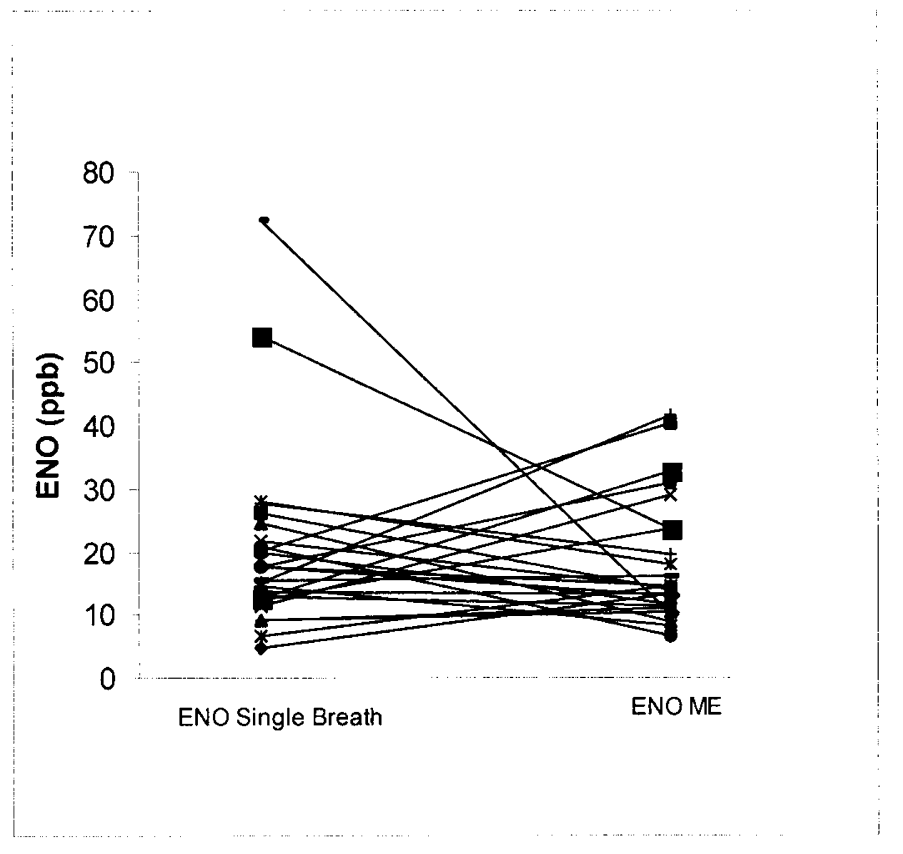

Figure 2. Comparison of ENO in 25 healthy children sampled by the SB and $\mathrm{ME}$ techniques. Measurements of ENO using the SB and ME techniques in the control group are shown. The mean ENO when measured by the SB was 20.23 $\pm 14.6 \mathrm{ppb}$ and $17.98 \pm 9.8 \mathrm{ppb}$ by the $\mathrm{ME}(p=0.19)$. This difference was not significant, with 10 of the 25 controls having a higher ME result.

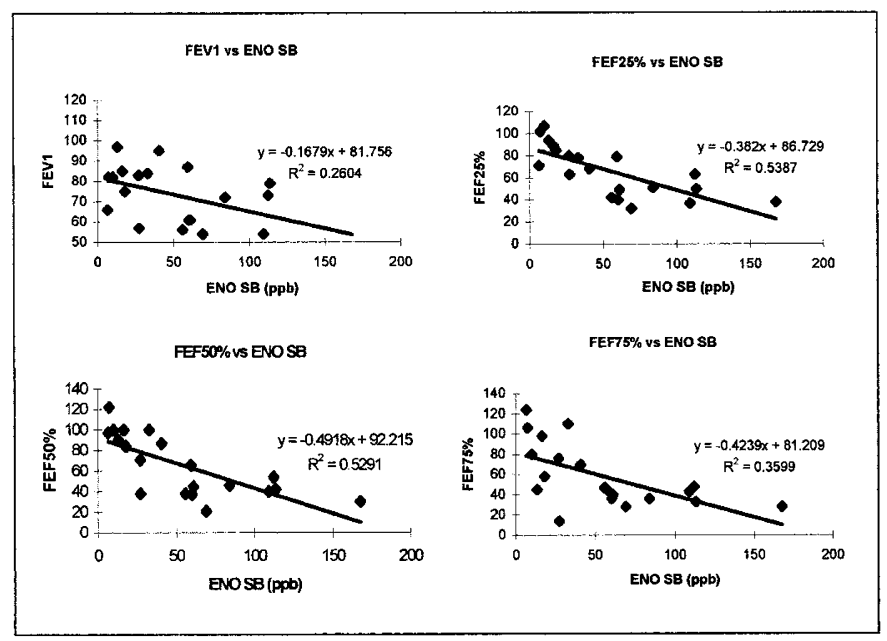

Figure 3. Regression analysis showing the relationship between spirometry results of the $\mathrm{FEV}_{1}, \mathrm{FEF}_{25}, \mathrm{FEF}_{50}$, and $\mathrm{FEF}_{75}$ with $\mathrm{ENO}$ when measured by the $\mathrm{SB}$ technique. The spirometry results of the $\mathrm{FEV}_{1}, \mathrm{FEF}_{25}, \mathrm{FEF}_{50}$, and $\mathrm{FEV}_{75}$ showed a highly significant negative correlation with ENO when measured by the SB $(p<0.05)$.

Regression analysis showed no significant correlation between ambient NO, which ranged from 3 to $108 \mathrm{ppb}$ (mean, $26.92 \mathrm{ppb})$, and ENO using the SB technique $\left(r^{2}=0.03, p>\right.$ $0.2)$.

\section{DISCUSSION}

We studied 25 normal children with a mean age of $12 \mathrm{y}$ and 20 asthmatic children with a mean age of $11.5 \mathrm{y}$. All were able to complete the study, and the majority preferred the SB as 


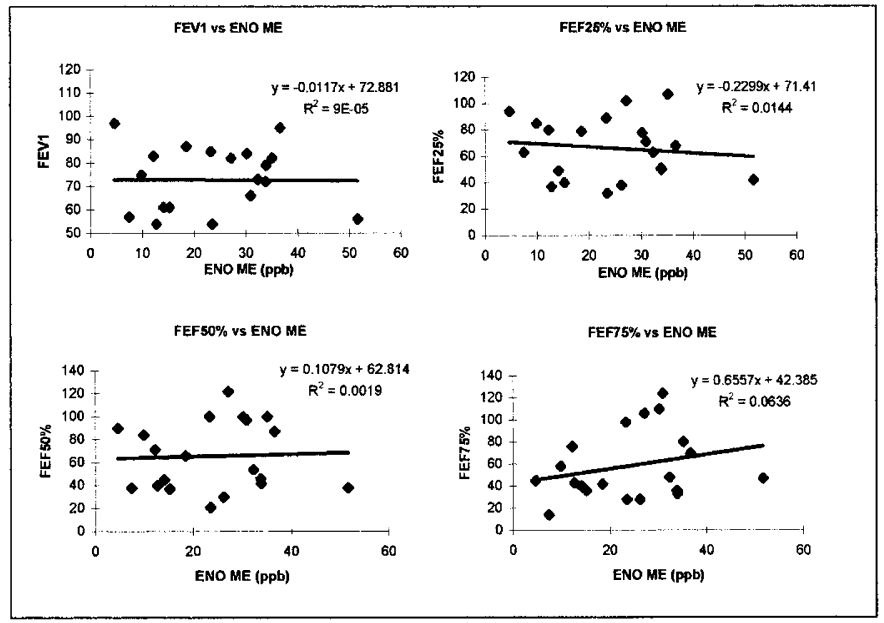

Figure 4. Regression analysis showing the relationship between spirometry results of the $\mathrm{FEV}_{1}, \mathrm{FEF}_{25}, \mathrm{FEF}_{50}$, and $\mathrm{FEF}_{75}$ with $\mathrm{ENO}$ when measured by the $\mathrm{ME}$ technique. The spirometry results of the $\mathrm{FEV}_{1}, \mathrm{FEF}_{25}, \mathrm{FEF}_{50}$, and $\mathrm{FEF}_{75}$ failed to show any significant correlation with ENO when measured by the ME technique.

they were more actively involved and found it more challenging.

The study compared two different ENO measuring methods in stable asthmatic children and healthy control subjects of the same age range. The results showed that there was a statistically significant difference between the mean ENO in the asthmatics versus the control children when measured by the $\mathrm{SB}$, with the asthmatics exhaling higher NO levels. These results are in agreement with the findings of Persson et al. (2), Alving et al. (3), and Barnes and Liew (16), and they back up the hypothesis that NO is an inflammatory mediator that has increased production in the lungs of asthmatics (17). The values for ENO in the control children were lower than the mean of $49.6 \mathrm{ppb}$ published by Byrnes and colleagues (18) with flow rates of $440 \mathrm{~mL} / \mathrm{min}$, similar to the 10 children studied twice by Franklin et al. (19) (18.8 ppb), but much higher than their total cohort (7.4 ppb), all using similar techniques. It remains difficult to explain the great variation in results from different laboratories apparently using the same methods. It is not helpful to compare our SB results on asthmatic children with others as it is well established that inhaled corticosteroids, which all our subjects were receiving, have a variable suppressant effect on ENO (18). This will also at least partially explain why there was considerable overlap between the results of the asthmatics and controls as inhaled corticosteroids can normalize ENO in asthmatic children (20).

It was also found that the NO levels exhaled by the asthmatic children were significantly higher when measured by the SB rather than by the ME. The ME technique, although feasible in young children and having the advantage that it can be carried out independently of the presence of an NO analyzer, showed that it is not sensitive in discriminating well between asthmatic and control children.

The ENO is highly flow dependent, and a small change in flow at low flows may cause a large change in ENO (4). The expiratory flow rates are inevitably higher with the ME technique as a single expiration takes up to $40 \mathrm{~s}$ using the SB technique. This might explain why the ME results were lower than the SB in the asthmatic children. An additional reason for the lower ENO values measured by the ME is the effect of dilution of the expired gases by air from the dead space of the equipment $(50 \mathrm{~mL})$. The dilution effect will obviously be dependent on the breathing pattern of the child and may explain the relatively poor results with this technique. However, this does not explain the fact that the differences between the $\mathrm{SB}$ and the ME results were limited to the asthmatic children.

In this study, NO-free air was only used for the ME tests. It has been claimed that the SB plateau values are independent of environmental NO, although high levels of pollution will tend to produce raised peak results (21). In this study the environmental NO exceeded $30 \mathrm{ppb}$ in eight of the studies on asthmatic and five of the control children. However, regression analysis showed a correlation between environmental NO and ENO that was both nonsignificant and negative, strongly supporting the claim that environmental $\mathrm{NO}$ has no influence on the results (21).

Another factor that could potentially affect the results is the order of the tests, as the SB technique was always performed first. However, there was always a delay of at least $10 \mathrm{~min}$ between the end of the SB and commencing the ME tests as both the equipment and the computer program had to be changed.

This study showed that orally exhaled NO concentration can be reliably sampled in children older than $9 \mathrm{y}$ of age by the SB technique. The use of the SB against a resistance prevents contamination of orally exhaled NO by nasal NO because of the early vellum closure $(21,22)$.

The spirometry results of the $\mathrm{FEV}_{1}, \mathrm{FEF}_{25}, \mathrm{FEF}_{50}$, and $\mathrm{FEV}_{75}$ showed a highly significant negative correlation with the ENO levels using the SB but not the ME technique. This indicates that the ENO levels measured by the SB correlate well with the degree of airway obstruction. To our knowledge, this is the first study to report on these correlations. As high levels of ENO are found in children with relatively mild but untreated asthma (23), these associations may be limited to those taking inhaled corticosteroids. Interestingly Baraldi and colleagues (20) failed to find a significant relationship between the fall in ENO and rise in $\mathrm{FEV}_{1}$ in children receiving a course of prednisolone for an acute asthma attack. A recent study (24) found a significant relationship between ENO and the prevalence of eosinophils in bronchial biopsy material from children with severe and poorly controlled asthma. Our study provides further support for the claim that ENO may be a useful additional and noninvasive method for monitoring airway pathology in severely asthmatic children.

The study performed by Ten Hacken et al. (25) showed that ENO concentrations measured by the ME technique in adults with stable asthma do not correlate with the $\mathrm{FEV}_{1}$. Our results are in agreement with the above. We further showed that none of the markers for flow limitation in the smaller airways$\mathrm{FEF}_{50}, \mathrm{FEF}_{75}$ - correlate with the ENO concentration measured by the ME technique. 


\section{CONCLUSIONS}

In summary, we have demonstrated that the $\mathrm{SB}$ technique for sampling ENO is a reliable and simple method that can discriminate between asthmatic and normal children, and correlates well with the degree of airway obstruction. The use of the ME technique remains unproven.

\section{REFERENCES}

1. Gustaffson LE, Leone AM, Persson MG, Wiklund NP, Monacada S 1991 Endogenous nitric oxide is present in the exhaled air of rabbits, guinea pigs and humans. Biochem Biophys Res Commun 181:852-857

2. Persson MG, Zetterstrom O, Agrenius V, Ihre E, Gustaffson 1994 LE. Single-breath nitric oxide measurements in asthmatic patients and smokers. Lancet 343:146-147

3. Alving K, Weitzberg E, Lundberg JM 1993 Increased amount of nitric oxide in exhaled air of asthmatics. Eur Respir J 6:1368-1370

4. Kissoon N, Duckworth L, Blake K, Murphy S, Silkoff P 1999 Exhaled nitric oxide measurements in childhood asthma: techniques and interpretation. Pediatr Pulmono 28:282-296

5. Byrnes CA, Dinarevic S, Busst C, Bush A, Shinebourne EA 1997 Is nitric oxide in exhaled air produced at airway or alveolar level? Eur Respir J 10:1021-1025

6. Dinarevic S, Byrnes CA, Bush A, Shinebourne EA 1996 Measurement of expired nitric oxide levels in children. Pediatr Pulmonol 22:396-401

7. Klanitonov SA, Yates D, Robbins RA, Logan-Sinclair, Shinebourne EA, Barnes PJ 1994 Increased nitric oxide in exhaled air of asthmatic patients. Lancet 343:133-136

8. Artlich A, Hagenah JV, Jonas S, Ahreys P, Gortner L 1996 Exhaled nitric oxide in childhood asthma. Eur J Pediatr 155:698-701

9. American Thoracic Society 1999 Statement. Recommendations for standardized procedures for the online and offline measurement of exhaled lower respiratory nitric oxide in adults and children. Am J Respir Crit Care Med 160:2104-2117

10. Jöbsis Q, Schellekens SL, Krosenbergen A, Hop WC, de Jongste JC 1999 Sampling of exhaled nitric oxide in children: end-expiratory plateau, balloon and tidal breathing methods compared. Eur Respir J 13:1406-1410
11. Kissoon N, Duckworth LJ, Blake KV, Murphy SP, Taylor CL, Silkoff PE 2000 $\mathrm{FE}(\mathrm{NO})$ : relationship to exhalation rates and online versus bag collection in healthy adolescents Am J Respir Crit Care Med 162:539-545

12. Archer SL, Shultz PJ, Warren JB, Hamph V, De Master EG 1995 Preparation of standards and measurements of nitric oxide, nitroxyl and related oxidation products. Methods Comparison. Methods Enzymol 7:21-34

13. Archer S 1993 Measurement of nitric oxide in biological models. FASEB J 7:349360

14. Hogman M, Stromberg S, Schedin U, Frostell C, Hedenstierna G, Gustaffson LE 1997 Nitric oxide from the human respiratory tract efficiently quantified by standardised single breath measurements. Acta Physiol Scand 159:345-346

15. Polgar G, Promadhat V 1974 Pulmonary Function Testing in Children: Techniques and Standards. WB Saunders, Philadelphia

16. Barnes PJ, Liew FY 1995 Nitric oxide and asthmatic inflammation. Immunol Today $16: 128-130$

17. Springall DR, Hamid QA, Buttery LKD 1993 Nitric oxide synthase induction in asthmatic human lung. Am Rev Respir Dis 147:A515(abstr)

18. Byrnes CA, Dinaveric S, Shinebourne EA, Barnes PJ, Bush A 1997 Exhaled nitric oxide measurements in normal and asthmatic children. Pediatr Pulmonol 24:312 318

19. Franklin PJ, Taplin R, Stick SM 1999 A community study of exhaled nitric oxide in healthy children. Am J Respir Crit Care Med 159:69-73

20. Baraldi E, Azzolin NM, Zanconato S, Dario C, Zacchello F 1997 Corticosteroids decrease exhaled nitric oxide in children with acute asthma. J Pediatr 131:381-385

21. Silkoff PE, McClean PA, Slutsky AS, Furlott HG, Hoffstein E, Wakita S, Chapman KR, Szalai JP, Zamel N 1997 Marked flow dependence of exhaled nitric oxide using a new technique to exclude nasal nitric oxide. Am J Respir Crit Care Med 155:260267

22. Jöbsis Q, de Jongste JC 1997 Comparison of three different sampling methods of exhaled nitric oxide in children. Am J Respir Crit Care Med 155:A970(abstr)

23. Artlich A, Busch T, Lewandowski K, Jonas S, Gortner L, Falke KJ 1999 Childhood asthma: exhaled nitric oxide in relation to clinical symptoms. Eur Respir J 13:1396140

24. Payne DNR, Adcock IM, Wilson NM, Oates T, Scallan M, Bush A 2002 Relationship between exhaled nitric oxide and mucosal eosinophilic inflammation in children with difficult asthma, after treatment with oral prednisolone. Am J Respir Crit Care Med $164: 1376-1381$

25. Ten Hacken NHT, Meijer RJ, Kerstjens HAM, Van der Mark TW, Postma DS 1996 Expired nitric oxide in stable asthmatic patients does not relate to parameters of disease severity. Eur Respir J 9(suppl 23):416S (abstr) 